\title{
Combustible Microemulsions with Diesel and Diesel Admixed with Rapeseed Oil
}

\begin{abstract}
FLORENTINA CRISTINA MIHAILESCU, MARIETA BALCAN, MONICA ELISABETA MAXIM, DAN FLORIN ANGHEL*
Colloid Laboratory, llie Murgulescu Institute of Physical Chemistry, Romanian Academy, 202 Splaiul Independentei, 060021, Bucharest, Romania

Novel results on combustible microemulsions prepared with diesel (D), blends of diesel and rapeseed oil (RSO), and mixtures of eco-friendly amphiphiles are presented. Water solubilization in oil/amphiphile systems was estimated by pseudo-ternary diagrams whereas the phase behavior by Winsor (W) diagrams. The extent of single-phase microemulsion (SPM) area depends on the amphiphile and oil phase composition. The presence of cosurfactant in the anionic-nonionic surfactant mixture increases verymuch the SPM area, but no effect is observed when half of D is replaced by RSO. In the pseudo-ternary phase diagram, the addition of organic electrolyte decreases the SPM areas. The microemulsions were characterized by the oill water interfacial tension $\left(\gamma_{w}\right)$, and the oil and water solubilization parameters $(S P)$ and $\left(S P{ }_{w}\right)$. The results obtained reveal that the $W 9 W 1$ microemulsions have minimal $\gamma_{\text {oow }}$ values, whereas $S P$ and $S P_{w}{ }_{w}$ are maximal. The work connects the phase behavior with the interfacial tension and the solubilization parameters of oil and water and is useful for obtaining and developing optimal microemulsions as alternative fuels.
\end{abstract}

Key words: combustible microemulsion, amphiphile, interfacial tension, solubilization parameters

Nowadays, a greater part of the world's energy comes from natural resources like crude oil, natural gas, coal, etc. Among them, crude oil is the most important because it is processed to diesel, petrol, kerosene, and other products for locomotion and heating [1]. For example, a recent Green Report unveils that nearly all the energy consumed by the transportation comes from liquid fuels and the need will increase to 104 million barrels/day (B/D) in 2030 and to 113 million B/D in 2040 [2]. This huge demand for fossil fuel has serious consequences on crude oil reservoirs that are steadily depleted generating unstable supply and fluctuating prices on the market [3]. At the same time, day-by-day the planet is more and more polluted by gases released into the atmosphere by fuel burning. The most dangerous of those gases are $\mathrm{CO}_{2}$ and nitrogen oxides ( $\mathrm{NO}_{\mathrm{x}}$ ) since they damage the environment, and threaten the lives of people and animals. Carbon dioxide is responsible for global warming through the greenhouse effect [4], while NO forms particulate matter (PM) [5]. Inhaled by humans, $\mathrm{PM}^{\mathrm{x}}$ generates severe respiratory and heart diseases, requiring long periods of hospitalization and high costs, and even death [6].

Due to the harmful effects of greenhouse gases, and because only $1.5 \%$ of the energy is currently coming from renewable sources [7], efforts have to be done to promoting such energy sources. On the other hand, a report of the UN Environment Program on the Future of Renewable Energies (REN 21) is more optimistic and estimates that about a quarter of the world's energy and fuel shall come from renewable sources in the next 15 to 20 years [8]. To accomplish such a task, a viable alternative is vegetable oils (VOs).

VOs are advantageous over diesel since they come from renewable and biodegradable sources are devoid of sulfur and aromatic hydrocarbons, their ecological footprint is nearly zero, and the exhaust is less toxic than those of diesel [9]. However, VOs have low volatility and high viscosity that prevent long-term engine fueling. These disadvantages can be overpassed by pyrolysis [10], cracking [11], transesterification [12], heating [13], emulsification [14] and microemulsification [15-17].
Among those methods, the most suitable is the microemulsification because allow partial or total replacement of diesel with vegetable oils $[15,18]$, introduce water into the fuel $[15,19]$, improve fuel atomization and burning [19], and reduce noxious emissions of $\mathrm{CO}_{2}, \mathrm{NO}_{x^{\prime}}$ particulate matter, and soot from exhaust gases [19].

The purpose of this work is to obtain combustible waterin-oil (w/0) microemulsions with diesel, and a blend of diesel and rapeseed oil (RSO) using eco and engine friendly chemicals. The importance and originality of the study rely on the development of an appropriate approach to design optimal microemulsions as alternative fuels for the diesel engine.

\section{Experimental part \\ Materials}

The amphiphiles(in this paper, the term amphiphile (A) designates any of surfactant (S), cosurfactant (C) or a mixture thereof) used in this work were the nonionic surfactant Tween 85 (T85) [polyoxyethylene (20) sorbitan trioleat] purchased from Sigma Aldrich, the anionic surfactant Synperonic A9C (SA9C) [sodium salt of alkyl $\left(\mathrm{C}_{13-15}\right)$ polyoxyethylene (PEO) (9) carboxymethylate] supplied by Imperial Chemical Industries, and the cosurfactant iso-butanol (B). The cosurfactant and sodium acetate $(\mathrm{NaAc})$ were obtained from Reactivul S. A. Bucharest, Romania. All chemicals were used as received. Their characteristics were elsewhere presented [20]. The oils were the commercial products Top Nordic Diesel (D) from PETROM S. A. Romania, and the rapeseed oil (RSO) from EXPUR S. A. Slobozia, Romania. They were purchased from the market and their technical characteristics were elsewhere given [20]. Millipore water was used throughout the experiments.

\section{Pseudo-ternary phase diagrams}

The investigated oil/water/surfactant-cosurfactant (OWSC) systems were prepared by using the pseudoternary phase diagrams as previously described [15]. The oil phase was diesel or diesel-RSO (1:1 wt.) blend. The

*email: adan@icf.ro, danflorin.anghel@gmail.com, Phone: (+40)723395101 
amphiphiles were the following mixtures: T85-B (2:1 wt.), T85-SA9C (1:1 wt.) and T85-SA9C-B (1:1:1 wt.). The performance of the investigated systems was estimated by the water solubilization limit, $\mathrm{W}_{\mathrm{m}}$, at various $\mathrm{SC} / 0$ weight ratios [21]. W was determined by titrating with water the $\mathrm{SC} / 0$ mixtures under stirring until the onset of turbidity or birefringence. The SC/O weight ratio of 1 was used to compare the water solubilization capacity in the investigated systems and that of 3:7 to design optimal fuel microemulsions.

\section{Winsor phase transitions}

The Winsor phase transitions were carried out in $10 \mathrm{~mL}$ screw cap vials. A fixed amount of surfactant-cosurfactant mixture $(9 \%, \mathrm{wt}$.) was put in each vial. Then, equal volumes $(4 \mathrm{ml})$ of oil and electrolyte solution were successively introduced into the vials. The concentration of the $\mathrm{NaAC}$ solution in the vials was increased in steps of $1 \%$ (wt.). The vials were capped, mechanically shaken for one week and then left to equilibrate at $25 \pm 1^{\circ} \mathrm{C}$. The volumes of the separated phases allowed estimating the Winsor (W) phase transitions from $\mathrm{W} \mathrm{I}(\mathrm{o} / \mathrm{W}$ microemulsion in equilibrium with excess oil) to W II (w/o microemulsion coexisting with excess water) via three-phase W III (middle bicontinuous microemulsion in equilibrium with both oil and water). The salinity corresponding to the microemulsion with equal volumes of solubilized oil and water was taken as optimal and denoted by S*.

\section{Oil/water interfacial tension $\left(\gamma_{\text {ow }}\right)$}

The oil/water interfacial tension, $\gamma_{\text {ow, }}$ was measured by the spinning drop interfacial tensiometer, Model SITE 100 Kruss, at $25 \pm 0.5^{\circ} \mathrm{C}$ [15]. The procedure was as follows: into the high-speed rotating capillary, the heavy phase was loaded first. Then, a drop of lighter phase was injected, and the angular velocity was increased to lengthen the drop to a cylindrical shape. The $\gamma_{\text {oww }}$, between the heavy and light phases, was determined according to equation (1):

$$
\gamma_{\text {oow }}=1 / 4\left(\Delta \rho \omega^{2} r^{3}\right)
$$

where, $\Delta \rho$ is the density difference between the two phases, $\omega$ is the angular velocity and $r$, the radius of the cylindrical drop, when the length of cylinder, $I$, is much bigger than $r$.

\section{Water and oil solubilization parameters}

During the $\mathrm{W} \mathrm{I} \rightarrow \mathrm{W} \mathrm{III} \rightarrow \mathrm{W}$ II Winsor phase transitions, the solubilization parameters of water (SP $)$ and oil (SP), were determined as in a previous paper [15]. They are the volume of water and respectively oil solubilized by surfactant unity of mass and are expressed in $\mathrm{mL} / \mathrm{g}$. The optimal solubilization parameter (SP*) is the highest value concomitantly reached by $\mathrm{SP}_{0}$ and $\mathrm{SP}_{w}$ in the salinity scan [15].

\section{Results and discussion \\ Phase diagrams}

Figure 1 shows the pseudo-ternary phase diagrams of the studied oil-amphiphile-water systems. The amphiphile compositions, given in the inset, show that all microemulsions contain T85 and diesel. The cosurfactant and $\mathrm{SA} 9 \mathrm{C}$ are present in three microemulsions, and in one microemulsion a half of the diesel is replaced by RSO. The system containing the T85-B amphiphile and diesel has the lowest solubilization capacity of water. The data in figure 1 reveal that within the amphiphile concentration range from 10 to $72 \%$, the amount of water solubilized into microemulsion does not exceed $10 \%$. The microemulsions with T85-SA9C mixture have a quite similar trend at amphiphile concentrations below 9.5\%. Afterward, the amount of water solubilized gradually increases, but is not higher than $14 \%$. At concentrations above $73 \%$, the microemulsions of those two amphiphile mixtures are gels, being impractical for combustibles. These attempts unveil the low water solubilization ability of T85 admixed with cosurfactant or with SA9C for water-in-oil combustible microemulsions.

Figure 1 shows a different picture for the systems with the T85-SA9C-B amphiphile. Irrespective of the oil phase, the microemulsions have large and almost equal singlephase areas and can accommodate large water amounts. The dotted lines at SC/O ratios of 1 and 3:7 are associated with the water solubilized in the w/o microemulsions. At $\mathrm{SC} / 0$ equal to $1, \mathrm{~W}_{\mathrm{m}}$ is around $61 \%$. The slight decrease in the solubilized water observed at the high water content for the system with D-RSO appears because RSO is more polar than diesel, and penetrates deeper into the oil/water interface increasing its thickness and curvature of the film. However, for a fuel candidate, the microemulsion must not contain more than $10 \%$ water. Otherwise, the heat of combustion lowers and weakens on the engine yield. This requirement is fulfilled by the $3: 7$ amphiphile/oil ratio dilution line.

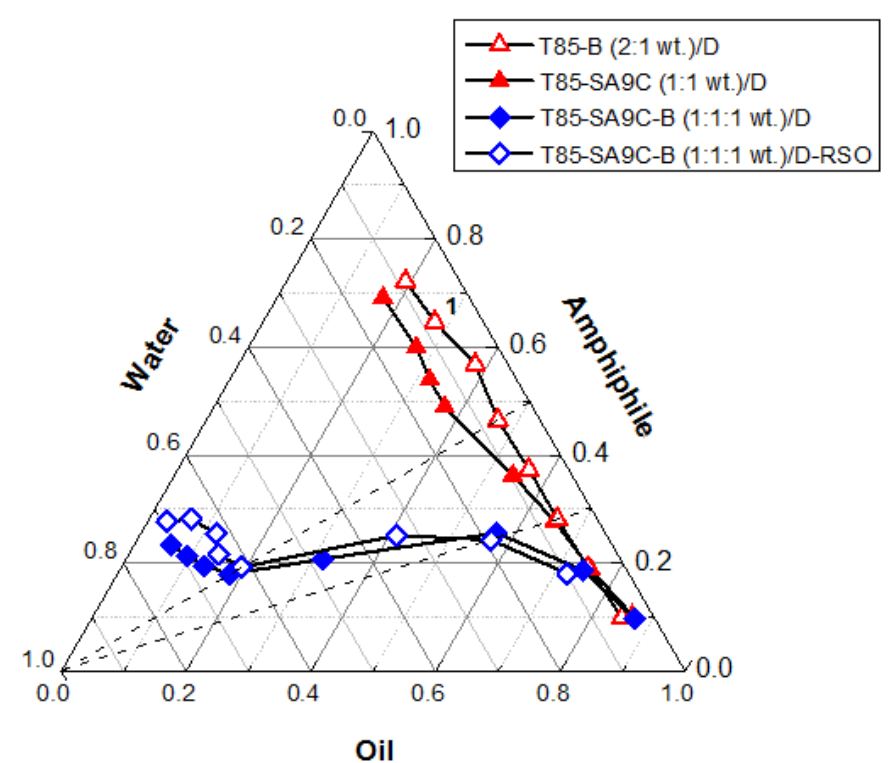

Fig. 1. Pseudo-ternary phase diagrams of oilamphiphile-water systems. The amphiphiles are given in inset, and one-phase microemulsion is denoted by 1 . 


\section{Winsor phase transitions}

The Winsor phase transitions sequence of diesel/water (NaAc)/T85-SA9C-B system as a function of electrolyte concentration is given in figure 2 . The data show a succession of vials containing two or three immiscible phases generated by increasing the NaAc concentration from $4 \%$ to $10 \%$. Vials \# $1-3$ contain 4 to $6 \% \mathrm{NaAc}$ and have a lower hazy liquid in equilibrium with a clear upper layer of oil. The turbidity of the lower layer increases with NaAc concentration because more diesel oil is solubilized into microemulsion. The lower layer is an oil-in-water or a Winsor I (W I) microemulsion that contains water, all the amphiphile, and growing amounts of oil as the $\mathrm{NaAc}$ concentration increases $[15,17]$. The next three vials (i.e., \#4-6) have three phases: a lower, a middle and an upper one, which appear within the NaAc concentration range from 7 to $9 \%$. The lower and the upper phases are limpid and consist of water and, respectively, oil with traces of amphiphile as was already described [22, 23]. The middle phase is very rich in amphiphile and contains both solubilized oil and water. All those \#4-6 vials are Winsor III (W III) systems having as a peculiarity the increase of excess water phase and the decrease of that of oil with electrolyte concentration. This phenomenon is associated with the gradual fade of turbidity of the middle layer denoting that the W III system is approaching the equilibrium.

Another fact is apparent in the vial \#5, where the excess volumes of water and oil are equal. The vial \#5 has an electrolyte concentration of $8 \% \mathrm{NaAc}$, and because the amounts of oil and water solubilized are equal, the microemulsion is designed as optimal. By further increase of NaAc concentration, vial \#7 has again two phases, a lower aqueous layer and an upper turbid one containing oil, amphiphile and some water. This is the Winsor II (W II) system, namely the water-in-oil (w/o) microemulsion. Such a microemulsion contains all the amphiphile and oil, and a small amount of water.

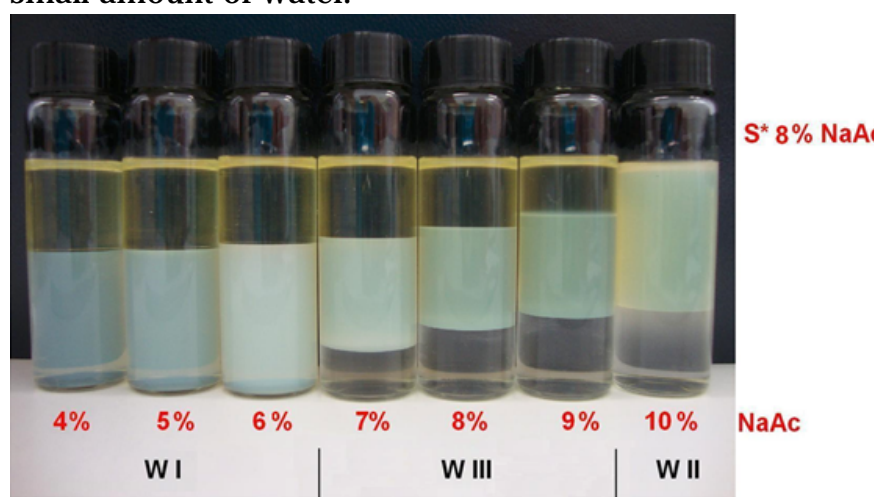

Fig. 2. Winsor phase diagram of diesel/water+ NaAc/(T85-SA9C-ibutanol, 1:1:1 wt.) system as a function of sodium acetate ( $\mathrm{NaAC}$ ) concentration. The NaAc concentration in the water of vials varies from 4 to $10 \%$, in steps of $1 \%$. (wt.). Optimal salinity ( $\left.\mathrm{S}^{*}\right)$ is in vial \#5, at $8 \%$ (wt.) NaAc.

In order to understand the phase transitions depicted in figure 1, one has to consider the effect of electrolyte on the amphiphile interaction with oil and water $[22,23]$. This can be done by means of the Winsor parameter, $R$, which is the ratio between the interaction of amphiphile with oil and with water, i.e., $R=A O / A W[24]$. At small electrolyte concentration, the interaction of SA9C surfactant with water prevails over that with oil, $R$ is lover than 1 , and generates W I systems. By increasing the NaAc concentration, NaAc competes with the carboxylate head group of SA9C for water of hydration. As a result, $R$ increases and a rich in surfactant W III phase, incorporating oil and water, is formed. At a threshold of NaAc concentration, which in this case is of $8 \%$, the microemulsion solubilizes almost equal volumes of oil and water as shown in figure 2. The microemulsion with this salinity is called optimal and is noted by $S^{*}$. In the optimal microemulsion, the interaction of amphiphile with oil and water is equal $(R=$ $1)$, the oil and water are solubilized as elongated domains separated by the amphiphile film and form a bicontinuous microemulsion as pointed out by Sabatini et al. [25]. At higher salinities, the interactions of surfactant with oil are stronger than with water $(R>1)$ and the system is in equilibrium with an excess of water, and a water-in-oil microemulsion or a W II structure forms.

\section{Oil/water interfacial tension}

Figure 3 illustrates changes in the oil/water interfacial tension, $\gamma_{\text {ww }}$, as a function of NaAc concentration during the phase transitions of the OWA system. At low electrolyte concentration, the systems are W insor I and the interfacial tensions between the two macroscopic phases are around $10^{-1} \mathrm{mN} / \mathrm{m}$. By increasing the salt concentration, $\gamma_{\text {ow }}$ gradually decreases to a minimum of $8.0 \times 10^{-2} \mathrm{mN} / \mathrm{m}$ situated at a $\mathrm{NaAc}$ concentration of $8 \%$. The $\mathrm{NaAc}$ concentration associated with the minimum of interfacial tension is denoted as optimal salinity for the respective system and is designed by $\gamma^{*}$. At $\gamma^{*}$ the microemulsion is able to solubilize practically equal amounts of oil and water. For a given oil and water phase, $\gamma^{*}$ is a good criterion for selecting the optimal amphiphile to formulate best microemulsions.

The value of $\gamma_{\text {ow }}$ is about 200 times lower than the diesel/ water interfacial tension [15]. After the $\gamma_{\text {ow }}$ minimum, further addition of NaAc produces a continuous increase of interfacial tension that attains values of $10^{-1} \mathrm{mN} / \mathrm{m}$ in the W II domain. This trend of $\gamma_{\text {in }}$ is similar to that previously reported for systems subjected to phase transitions by salts $[23,26]$.

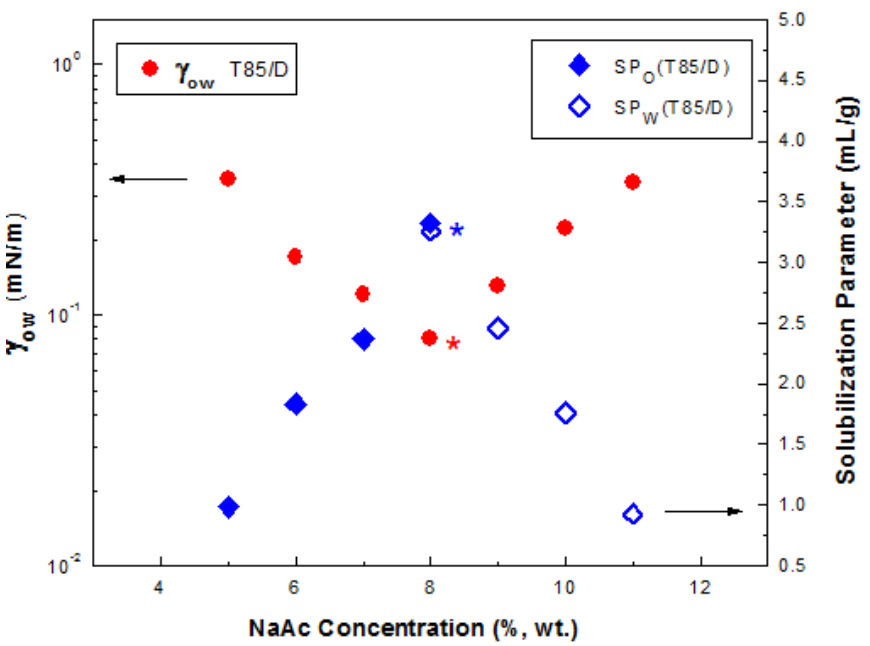

Fig. 3. The effect of $\mathrm{NaAc}$ concentration on the interfacial tension $\left(\gamma_{\text {ow }}\right)$, and solubilization parameters of oil $\left(\mathrm{SP}_{0}\right)$ and water $\left(\mathrm{SP}_{\mathrm{w}}\right)$ for the systems containing T85, SA9C, B. The oil phase was diesel (D).

The star points mark the lowest values of $\gamma$ for the respective systems.

The decrease of $\gamma_{\text {ow }}$ to ultralow values in the WIII region is due to the amphiphile film formed at the oil/water interface of microemulsion. The film is generated by the unique combination of the extended AC9Na anionic surfactant with the T85 nonionic surfactant and $i$-butanol. During the process of film formation, the amphiphile molecules optimize the interfacial area until the smallest 
lateral interactions and contact with water and oil are reached and the minimal interfacial tension value, $\gamma^{*}$, is attained. The different $\gamma^{*}$ values recorded during the formulation process of microemulsions are due to the curvature of the monolayer film, which is governed by the structure of amphiphile molecules, their reciprocal interactions, and the interplay with the antagonist oil and water adjacent phases [24]. These data point out that the lowest value of the oil/water interfacial tension can be obtained by a proper selection of amphiphile, the oil, and the water phases and of all the other components that assist in microemulsion formulation.

\section{Oil and water solubilization parameters}

Figure 3 also shows changes of the solubilization parameters of oil (SP) and water (SP $)$ as a function of NaAc concentration. The picture reveals that in a WOA system undergoing the $\mathrm{W} \mathrm{I} \rightarrow \mathrm{W}$ III $\rightarrow$ W II phase transition, salt addition increases the $\mathrm{SP}$ and decreases the $\mathrm{SP}_{\mathrm{P}}$. These parameters meet at an apex situated within the WWII phase. For the studied system, NaAc addition increases the SP to a maximum of $3.32 \mathrm{~mL} / \mathrm{g}$ at a salinity of $8 \% \mathrm{NaAc}$. At the same salinity, $\mathrm{SP}$ is high and equal to $3.28 \mathrm{~mL} / \mathrm{g}$ and gradually decreases by salt addition. At $8 \%$ $\mathrm{NaAc}, \mathrm{SP}$ and SP have almost the same value denoting that equal amounts of oil and water are solubilized by the amphiphile into the microemulsion. This is due to the equilibrated film build up by the amphiphile atthe oil/water interface.

The phenomenon can be explained assuming that the electrolyte diminishes the repulsions between the carboxylate head groups of the extended anionic surfactant. As a result, the hydrophilic interactions diminish on behalf of the hydrophobic ones until the two interactions reach the equilibrium and equal volumes of oil and water are solubilized in microemulsion. The crossing point at almost equal values of $\mathrm{SP}_{0}$ and $\mathrm{SP}_{w}$ corresponds to the point within the WIII region where the middle phase microemulsion coexists with approximately equal volumes of excess oil and water. The point is designed as the optimal solubilization parameter (SP*) and coincides with $\gamma^{*}$ and with the optimal formulation as pointed out in previous works [15].

From these data is apparent that the higher the apex, the bigger the amount of oil and water solubilized by the amphiphile unitary mass. Therefore, the SP* is, in turn, a useful criterion to designate and formulate the optimal microemulsion.

\section{Conclusions}

The results obtained in this work unveil thateco-friendly amphiphiles such as the extended anionic surfactant SA9C together with the nonionic surfactant $T 85$, and the $i$-butanol cosurfactant are able to formulate w/o microemulsions with diesel and diesel-rapeseed oil mixtures. The formulation process was conducted by pseudo-ternary phase diagrams showed that the amphiphile mixture gives big microemulsion areas able to solubilize large amounts of water. During the W I $\rightarrow$ W III $\rightarrow$ W II phase transition resulted by increasing the sodium acetate concentration, the phase behavior of the oil-water-amphiphile system correlates well with the variation of interfacial tension, and the oil and water solubilization. In the Winsor III systems at the optimal salinity, the interfacial tension is minimal, and the oil and water solubilization parameters are the highest. The diesel-rapeseed oil microemulsions have similar phase diagrams with those of diesel, and recommend the vegetable oil for fuel microemulsions. The results of this study contribute to the advancement of knowledge aboutliquid-liquid dispersions, and are a means of acquiring efficient and eco-friendly microemulsion-fuels. The microemulsions described in this work are currently in studies concerning the fuel relevant characteristics such as stability in time and with temperature, flow behavior on a large temperature scale, cloud point, pour point and calorific power.

\section{References}

1.TEMPLE J ., from https://w ww.technologyreview.com/s/610457/at-thisrate-its-going-to-take-nearly-400-years-to-transform-the-energy-system/ Accessed April 20, 2019.

2.ZAHARIA, C., from https://www.green-report.ro/Combustibilii-fosilivor-continua-sa-domine-lumea-pentru-urmãtoarele-douã-decade/. Accessed March 22, 2019.

3.*** US Energy Information Agency (EIA), from https://ww w.eia.gov/ forecasts/steo/report/prices.cfm. Accessed May 7, 2019.

4.KOJ IMA, N., TOKAI, A., NAKAKUBO, T., NAGATA, Y., Environ. Syst. Decis., 36, 2016, p. 229.

5.RAO, S., CHIRKOV, V., DENTENER. F., VAN DINGENEN, R., PACHAURI. S., PUROHIT, P., AMANN, M., HEYES, C., KINNEY, P., KOLP, P., KLIMONT, Z., RIAHI, K., SCHOEPP, W., Environ. Model Assess., 17, 2012, p. 613. 6.LELIEVELD, J., EVANS, J.S., FNAIS, M., GIANNADAKI, D., POZZER, A., Nature, 525, 2015, p. 367.

7.COBB, K., from https://oilprice.com/Alternative-Energy/RenewableEnergy/The-Harsh-Reality-Of-A-Global-Energy-Transition.html. Accessed March 22, 2019.

8.*** UN Environment Program on the Future of Renewable Energies (REN 21) from http://www.ren21.net/wp-content/uploads/2017/10/GFRFull-Report-2017_webversion_3.pdf. Acccessed March 22, 2019.

9.HELLIER, P., LADDOMMATOS, N., YUSAF, T., Fuel, 143, 2015, p. 131.

10.XU J.M., JIANG, J.C., LU, YJ, CHEN, J., Bioresour. Technol., 100, 2009, p. 4867.

11.ISHIHARA, A., TSUKAMOTO, T., HASHIMOTO, T., NASU, H., Catal. Today, 303, 2018, p. 123.

12.LEUNG, D.Y.C., WU, X., LEUNG, M.K.H., Appl. Energ., 87, 2010, p. 1083.

13.PRABU, S.S., ASOKAN, M.A., PRATHIBA, S., AHMED, S., PUTHEAN, G., Renew. Energy, 122, 2018, p. 196.

14.SEIFI, M.R., HASSAN-BEYGI, S.R., GHOBADIAN, B., DESIDERI, U., ANTONELLI, M., Fuel, 166, 2016, p. 392.

15BALCAN, M., MIHAILESCU, F.C., ANGHEL, D.F., VACARESTEANU, I.C., ARICOV, L., VASILESCU, E.L., Fuel, 117, 2014, p. 251.

16.QI, D.H., YANG, K., ZHANG, D., CHEN, B., WEI, Q., ZHANG, C.H., Renewable Energy, 113, 2017, p. 1201.

17.NAJJAR, R., HEIDARI, S., Fuel, 214, 2018, p. 497.

18.ACHARYA, B., GURU, P.S., DASH, S., Fuel, 171, 2016, p. 87.

19.OCHOTERENA, R., LIF, A., NYDEN, M., ANDERSSON, S., DENBRATT, I., Fuel, 89, 2010, p. 122.

20.MIHAILESCU, F.C., PhD Thesis, Ilie Murgulescu Institute of Physical Chemistry, Romanian Academy, Bucharest, Romania, 2019.

21.GARTI, N., ASERIN, A., EZRAHI, S., WACHTEL, E., J. Colloid Interface Sci., 169, 1995, p. 428.

22.ANGHEL, D.F., Progr. Colloid Polym. Sci., 83,1990, p. 188.

23. ANGHEL, D.F., MIRCIOAGA, I., ELLIS, D.R., DUFF, E.A., Rev. Roum. Chim., 35, 1990, p. 891.

24.SALAGER, J.L., ANTON, R.E., SABATINI, D.A., HARWELL, J.H., ACOSTA, E.J., TOLOSA, L.I., J. Surfact. Deterg., 8, 2005, p. 3.

25.DO, L.D., WITHAYAPAYANON, A., HARWELL, J.H., SABATINI, D.A., J . Surfact. Deterg., 12, 2009, p. 91.

26.WITTHAYAPANYANON, A., ACOSTA, E.J ., HARWELL, J.H., SABATINI, D.A., J. Surfact. Deterg., 9, 2006, p. 331.

Manuscript received: 3.06 .2019 